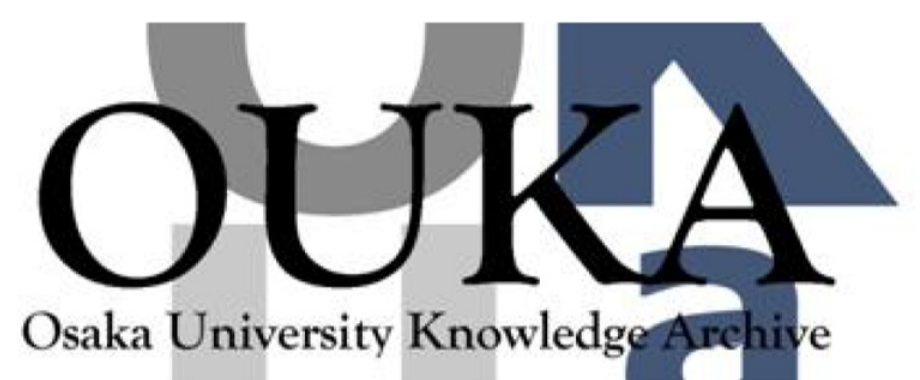

\begin{tabular}{|c|l|}
\hline Title & $\begin{array}{l}\text { Dependence of alkyl-substituent length for bulk } \\
\text { heterojunction solar cells ut i lizing } \\
1,4,8,11,15,18,22,25-\text { octaalkylphthalocyanine }\end{array}$ \\
\hline Author(s) & $\begin{array}{l}\text { Hori, Tetsuro; Miyake, Yasuo; Masuda, Tetsuya } \\
\text { et al. }\end{array}$ \\
\hline Citation & $\begin{array}{l}\text { Journal of Photonics for Energy. 2(1) p. 021004- } \\
1-p .021004-7\end{array}$ \\
\hline Issue Date & $2012-03-02$ \\
\hline oaire:version VoR \\
\hline URL & https://hdl. handle. net/11094/75926 \\
\hline rights & \\
\hline Note & \\
\hline
\end{tabular}

Osaka University Knowledge Archive : OUKA

https://ir. Library. osaka-u. ac. jp/

Osaka University 


\section{Photonics for Energy}

\section{Dependence of alkyl-substituent length for bulk heterojunction solar cells utilizing $1,4,8,11,15,18,22,25-$ octaalkylphthalocyanine}

Tetsuro Hori

Yasuo Miyake

Tetsuya Masuda

Takeshi Hayashi

Kaoru Fukumura

Hiroyuki Yoshida

Akihiko Fujii

Yo Shimizu

Masanori Ozaki 


\title{
Dependence of alkyl-substituent length for bulk heterojunction solar cells utilizing 1,4,8,11,15,18,22,25-octaalkylphthalocyanine
}

\author{
Tetsuro Hori, ${ }^{a}$ Yasuo Miyake,,${ }^{a, b}$ Tetsuya Masuda, ${ }^{\text {a }}$ Takeshi Hayashi, \\ Kaoru Fukumura, ${ }^{a}$ Hiroyuki Yoshida, ${ }^{a}$ Akihiko Fujii, \\ Yo Shimizu, ${ }^{b}$ and Masanori Ozaki ${ }^{a}$ \\ ${ }^{a}$ Osaka University, Division of Electrical, Electronic and Information Engineering, \\ Graduate School of Engineering, 2-1 Yamada-oka, Suita, Osaka 565-0871, Japan \\ afujii@eei.eng.osaka-u.ac.jp \\ ${ }^{b}$ National Institute of Advanced Industrial Science and Technology, Synthetic \\ Nano-Function Materials Group, Research Institute for Ubiquitous Energy Devices, \\ Kansai Center, 1-8-31 Midorigaoka, Ikeda, Osaka 563-8577, Japan
}

\begin{abstract}
Bulk heterojunction organic thin-film solar cells utilizing soluble phthalocyanine derivatives, 1,4,8,11,15,18,22,25-octaalkylphthalocyanine $\left(\mathrm{CnPcH}_{2}, \mathrm{n}=6,7,9,10\right)$, were investigated. Two broad peaks existing in the external quantum efficiency spectra almost correspond to the Q-band and B-band of $\mathrm{CnPcH}_{2}$. The solar cell utilizing $\mathrm{C}_{6 \mathrm{PcH}}$ had the best photovoltaic properties as evidenced by open-circuit voltage, short-circuit current density, fill factor, and energy conversion efficiency. Almost the same photovoltaic properties were observed in the solar cells utilizing $\mathrm{C}_{9} \mathrm{PcH}_{2}$ and $\mathrm{C}_{10 \mathrm{PcH}_{2}}$. We discuss the photovoltaic properties by taking into consideration the crystal structure and electronic state of $\mathrm{CnPcH}_{2}$ from the results of the absorbance spectra, X-ray diffraction measurement, and polarization microscope observation. ( 2012 Society of Photo-Optical Instrumentation Engineers (SPIE). [DOI: 10.1117/1.JPE.2.021004]
\end{abstract}

Keywords: organic thin-film solar cells; bulk heterojunction; phthalocyanine; solution process; 1,4,8,11,15,18,22,25-octaalkylphthalocyanine.

Paper 11226SSP received Sep. 22, 2011; revised manuscript received Nov. 29, 2011; accepted for publication Dec. 12, 2011; published online Mar. 2, 2012.

\section{Introduction}

Organic thin-film solar cells utilizing organic semiconductors have attracted considerable attention as next-generation solar cells ${ }^{1}$ from the viewpoint of light weight, flexibility, and low cost. Such organic semiconductors are classified into two types: $\pi$-conjugated polymers and those having low molecular weight. Organic thin-film solar cells based on $\pi$-conjugated polymers have been investigated since the discovery of photoluminescence quenching, ${ }^{2}$ photoinduced charge transfer, ${ }^{3}$ and photoconduction enhancement ${ }^{4}$ in $\pi$-conjugated polymer-fullerene systems. Organic thin-film solar cells with a bulk heterojunction active layer fabricated by a wet process achieved high energy conversion efficiency. ${ }^{5,6}$ Wet processes are also important for the large area fabrication ${ }^{7}$ of organic thin-film solar cells.

On the other hand, some low-molecular-weight semiconductors demonstrate high crystallinity and charge mobility by intermolecular interactions; however, they are inappropriate for wet processes because of their poor solubility in typical organic solvents. Therefore, organic thinfilm solar cells with a layered ${ }^{1}$ or $\mathrm{p}$-i-n structure ${ }^{8}$ based on low-molecular-weight materials generally have been fabricated by thermal evaporation under vacuum. Recently, some groups have investigated solution-processable organic thin-film solar cells utilizing low-molecular-weight molecules, ${ }^{9}$ but device performance has still been low.

0091-3286/2012/\$25.00 (C) 2012 SPIE 


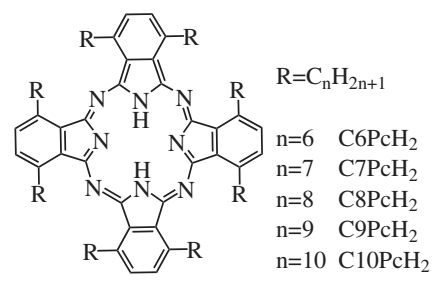

Fig. 1 Molecular structure of $\mathrm{CnPcH}_{2}$.

The control of intermolecular interactions is one of the most important strategies for the molecular design of organic semiconductors. The introduction of appropriate substituents is effective for the realization of a large area of uniform molecular packing for organic devices. Recently, we have demonstrated high hole and electron drift mobilities of $1.4 \mathrm{~cm}^{2} / \mathrm{Vs}$ and $0.5 \mathrm{~cm}^{2} / \mathrm{Vs}$ in the crystalline phase of a mesogenic phthalocyanine derivative, $1,4,8,11,15,18,22,25$-octahexylphthalocyanine $\left(\mathrm{C} \mathrm{PcH}_{2}\right.$, shown in Fig. 1), which was evaluated by means of time-of-flight (TOF) measurements. ${ }^{10,11} \mathrm{C}_{6} \mathrm{PcH}_{2}$ can be spread on a substrate from the solution and exhibits a mesogenic phase within a certain temperature range, ${ }^{12}$ which indicates that it can be used as a low-molecular-weight donor material for film fabrication by a solution process and for realizing high-performance bulk heterojunction organic solar cells.

$\mathrm{C} \mathrm{PcH}_{2}$ could be mixed in a conventional solvent with a typical acceptor molecule, such as 1-(3-methoxy-carbonyl)-propyl-1-1-phenyl-(6,6)C61 (PCBM), and the films fabricated by a solution process are available as a bulk heterojunction active layer in organic solar cells. Recently, we reported on a simple organic solar cell with bulk heterojunction of $\mathrm{C}^{2} \mathrm{PcH}_{2}$ and PCBM fabricated by spin-coating, and demonstrated the high energy conversion efficiency of $3.1 \%$ and external quantum efficiency (EQE) higher than $70 \%$ at the Q-band region. ${ }^{13}$ Moreover, we reported on the active layer thickness dependence, hole transport buffer layer dependence, and tandem structure in an organic thin-film solar cell utilizing $\mathrm{C}_{6 \mathrm{PcH}}{ }_{2}{ }^{14}$

The properties of organic semiconductors, such as poly(3-alkylthiophene), strongly depend on the alkyl-substituent length. ${ }^{15}$ Therefore, alkyl-substituent length must be an important parameter for determining the electrical properties of $\mathrm{CnPcH}_{2}$. Actually, $\mathrm{C} 8 \mathrm{PcH}_{2}$ exhibited different alignment and electrical properties than $\mathrm{C} \mathrm{PcH}_{2} \cdot{ }^{16,17}$ In this paper, we report on the alkylsubstituent length dependence of $\mathrm{CnPcH}_{2}$ for simple bulk heterojunction organic solar cells.

\section{Experimental Details}

$\mathrm{CnPcH}_{2}$ was synthesized according to the literature ${ }^{18}$ with slight modifications and fully purified by column chromatography (silica-gel with toluene as eluent) followed by repetitive recrystallization from toluene-methanol $(1: 2)$ solution. PCBM was purchased from Frontier Carbon Ltd.

The poly(3,4-ethylenedioxythiophene):poly(styrenesulfonate) (PEDOT:PSS, Baytron P VP AI 4083) was spin-coated onto an indium-tin-oxide (ITO)-coated quartz substrate at $1000 \mathrm{rpm}$ for $60 \mathrm{~s}$ by using an aqueous solution diluted with the same volume of isopropanol and was dried at $100^{\circ} \mathrm{C}$ for $10 \mathrm{~min}$ in an oven under atmospheric conditions. The thickness of the PEDOT:PSS layer was estimated to be approximately $60 \mathrm{~nm}$. The thickness was estimated by atomic force microscopy.

$\mathrm{CnPcH}_{2}$ and PCBM were dissolved in chloroform solvent, and the composite ratio of $\mathrm{CnPcH}_{2}: \mathrm{PCBM}$ was $2: 1$ by weight. ${ }^{13}$ The $\mathrm{CnPcH}_{2}: \mathrm{PCBM}$ mixed solution was spin-coated onto the PEDOT:PSS layers at $500 \mathrm{rpm}$ for $60 \mathrm{~s}$ in a glove box filled with argon gas. The thickness of the active layer was estimated to be approximately $150 \mathrm{~nm}$.

An aluminum layer as a counter electrode to the ITO was deposited onto the composite layers through shadow masks by thermal evaporation under a pressure of approximately $10^{-4} \mathrm{~Pa}$. The evaporation speed and thickness of the Al layer were approximately $5 \AA / s$ and $80 \mathrm{~nm}$, respectively. The active area of the solar cell was $2 \times 2 \mathrm{~mm}^{2}$.

The absorbance spectra were measured using a spectrophotometer (Shimadzu UV-3150). X-ray diffraction (XRD) patterns were measured using a Rigaku X-ray diffractometer (RINT 
1100). The polarizing photomicrographs were measured by using a polarized optical microscope (Olympus BX50).

Carrier mobility was determined by the time-of-flight (TOF) technique. A $\mathrm{N}_{2}$-pulsed laser (337 nm, $800 \mathrm{ps)} \mathrm{was} \mathrm{used} \mathrm{to} \mathrm{generate} \mathrm{the} \mathrm{photocarrier.} \mathrm{The} \mathrm{dc} \mathrm{bias} \mathrm{was} \mathrm{applied} \mathrm{by} \mathrm{batteries.}$ Transient photocurrents were detected by a digital oscilloscope (Hewlett Packard Infinium 54820A) with the help of a wide-band preamplifier. The mobility, $\mu$ was calculated by the equation $\mu=d^{2} / V \tau_{s}$, where $d, V$, and $\tau_{s}$ are sample distance, applied bias, and the transit time, respectively.

The photocurrent spectra were measured with a programmable electrometer (Keithley 617S) by using a xenon lamp light passing through a monochromator as a light source, and EQE was estimated for each incident light wavelength using the equation $\mathrm{EQE}(\%)=$ $1240 \times I\left(\mathrm{~A} / \mathrm{cm}^{2}\right) \times 100 /\left(\lambda(\mathrm{nm}) \times P_{\text {in }}\left(\mathrm{W} / \mathrm{cm}^{2}\right)\right.$, where $I$ is the photocurrent density and $\lambda$ is the wavelength of incident light. The current-voltage characteristics were measured with a high-voltage-source measurement unit (Keithley 237) under AM1.5G (100 mW/ $\mathrm{cm}^{2}$ ) solarilluminated conditions. From the current-voltage characteristics under AM1.5G, the FF and energy conversion efficiency $\left(\eta_{e}\right)$ were estimated according to the following definitions: $\mathrm{FF}=$ $I_{\max } V_{\mathrm{max}} / I_{\mathrm{sc}} V_{\mathrm{oc}}$ and $\eta_{e}=I_{\mathrm{sc}} V_{\mathrm{oc}} \mathrm{FF} / P_{\mathrm{in}}$, where $I_{\max }$ and $V_{\mathrm{max}}$ are the current density and voltage at the maximum output power, respectively; $V_{\mathrm{oc}}$ is the open-circuit voltage; $I_{\mathrm{sc}}$ is the short-circuit current density; and $P_{\text {in }}$ is the intensity of the incident light. The current-voltage characteristics and EQE spectra were measured in a vacuum at room temperature.

\section{Results and Discussion}

Organic molecules such as porphyrins, phthalocyanines, and their derivatives exhibit anomalous optical characteristics because of their molecular ring structures. It is well known that they possess two kinds of energy bands, Q-band and B-band, in the case of phthalocyanines. ${ }^{19}$

Figure 2(a) shows the absorption coefficient spectra of $\mathrm{CnPcH}_{2}$ molecules in a chloroform solution. The concentration of solution is $1 \times 10^{-5} \mathrm{~mol} / \mathrm{L}$, and the optical path length is $1 \mathrm{~cm}$. Figure 2(b) shows the absorbance spectra of $\mathrm{CnPcH}_{2}$ thin films with thickness of $150 \mathrm{~nm}$. The absorption coefficient spectra were independent of substituent length in a solution condition, and the absorption peak wavelengths of the Q-band were 700 and $730 \mathrm{~nm}$. It is thought that the photoabsorption originates from the electronic transition of the ring $\pi$-conjugation on phthalocyanine and that the electronic energy states are independent of the substituent length in an isolated condition in the solution.

The absorbance spectra of thin films at the Q-band region differed between $\mathrm{C}^{-\mathrm{PcH}_{2}}$ and the other $\mathrm{CnPcH}_{2}$. The absorption peak wavelengths at the Q-band region of $\mathrm{C} \mathrm{PcH}_{2}$ were 670 and $740 \mathrm{~nm}$, and those of the other $\mathrm{CnPcH}_{2}$ thin films were split around 640 and $770 \mathrm{~nm}$. Moreover, the absorbance peak of $\mathrm{C} \mathrm{PcH}_{2}$ was 0.75 , and that of the other $\mathrm{CnPcH}_{2}$ was about 0.5. It might be indicated that the different alignment of molecules in the $\mathrm{C}_{6} \mathrm{PcH}_{2}$ film and the other $\mathrm{CnPcH}_{2}$ films contribute to each electronic state.
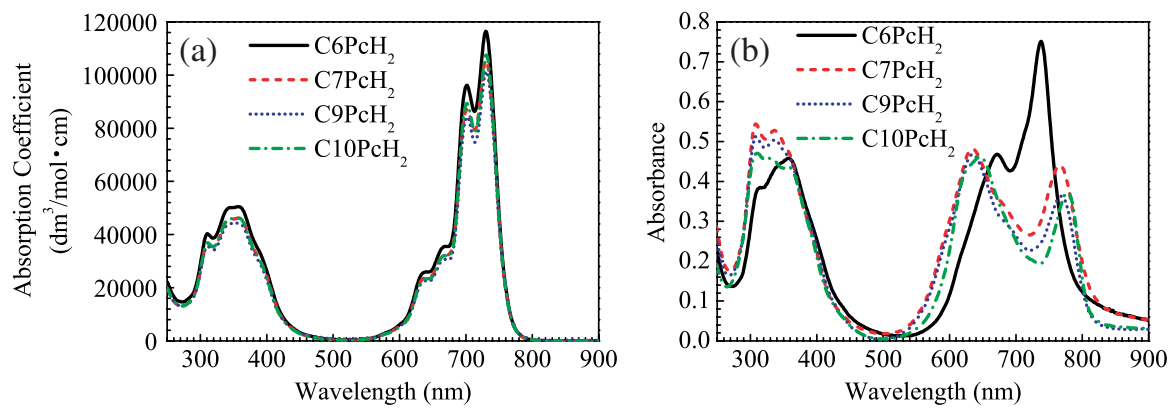

Fig. 2 (a) Absorption coefficient spectra of $\mathrm{CnPcH}_{2}$ solution whose solvent is chloroform and (b) absorbance spectra of $\mathrm{CnPcH}_{2}$ thin films, the thickness of which was $150 \mathrm{~nm}$ on quartz substrate. 

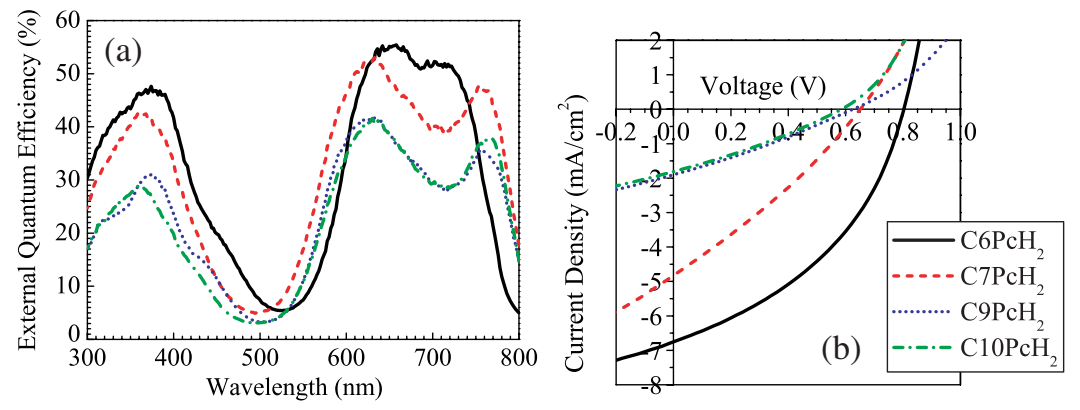

Fig. 3 (a) EQE spectra and (b) current density-voltage characteristics, with the solar cells under AM1.5G (100 nW/ $\left.\mathrm{cm}^{2}\right)$ solar-illuminated conditions, with ITO/PEDOT:PSS/CnPcH ${ }_{2}: \mathrm{PCBM} / \mathrm{Al}$ structures.

Figure 3(a) shows the EQE spectra of the solar cells with a $\mathrm{CnPcH}_{2}: \mathrm{PCBM}$ active layer. Two broad peaks that almost correspond to the absorbance spectra in Fig. 2(b) are visible in the EQE spectra. The EQEs at both the 670 and $740 \mathrm{~nm}$ regions of the solar cell utilizing $\mathrm{C} \mathrm{PcH}_{2}$ were around $50 \%$ in spite of the different absorbance. Though the incident light of $740 \mathrm{~nm}$ was efficiently absorbed around the film surface, the generated charges could not reach the counter electrode.

The current-voltage characteristics of the solar cells utilizing $\mathrm{CnPcH}_{2}$ under the AM1.5G $\left(100 \mathrm{~mW} / \mathrm{cm}^{2}\right)$ solar-illuminated condition are shown in Fig. 3(b). The highest photovoltaic properties in all parameters of $V_{\mathrm{oc}}, I_{\mathrm{sc}}, \mathrm{FF}$, and $\eta_{e}$ were observed in the solar cell utilizing $\mathrm{C}_{6 \mathrm{PcH}}$. The performance parameters of the solar cells utilizing $\mathrm{CnPcH}_{2}$ are summarized in Table 1. It is thought that the difference in $V_{\text {oc }}$ also suggests that the electronic states between $\mathrm{C}_{6 \mathrm{PcH}}$ and the other $\mathrm{CnPcH}_{2}$ 's are different.

Figure 4 shows the XRD patterns of the $\mathrm{CnPcH}_{2}: \mathrm{PCBM}$ bulk heterojunction films. In the XRD pattern of $\mathrm{C} \mathrm{PcH}_{2}$, a large diffraction peak corresponding to the distance of the hexagonal column was observed at around $2 \theta=4.86 \mathrm{deg}$, and the second to the fourth harmonic diffraction peaks were also observed. It is thought that $\mathrm{C} \mathrm{PcH}_{2}$ formed hexagonal columnar structures with large domains in the bulk heterojunction film. On the other hand, in XRD patterns of the other $\mathrm{CnPcH}_{2}$ 's, the diffraction intensities were weaker than those of $\mathrm{C} \mathrm{PcH}_{2}$, and two large diffraction peaks corresponding to the rectangular columnar structure appeared at around $2 \theta=$ 4.27 and $4.78 \mathrm{deg}$ in $\mathrm{C}_{7 \mathrm{PcH}}, 2 \theta=3.96$ and $4.25 \mathrm{deg}$ in $\mathrm{C}_{2} \mathrm{PcH}_{2}$, and $2 \theta=3.65$ and $4.49 \mathrm{deg}$ in $\mathrm{C}_{10 \mathrm{PcH}_{2}}$. Moreover, many small diffraction peaks were observed. These observations indicate that $\mathrm{C} \mathrm{PcH}_{2}$ has several domains with single hexagonal columnar alignment and that the other $\mathrm{CnPcH}_{2}$ 's have many domains with various alignments mainly including the rectangular columnar alignment. In the rectangular structure, the column distance should be longer than the hexagonal structure, and the carriers are not transported easily between columns. As a result, the differences in the crystalline structure, such as the domain size of single alignment and the column distance, must be the main reason for the superiority of the electrical properties in $\mathrm{C}_{6} \mathrm{PcH}_{2}$ : $\mathrm{PCBM}$ bulk heterojunction film.

Figure 5 shows polarizing photomicrographs of $\mathrm{CnPcH}_{2}$ at $25^{\circ} \mathrm{C}$ between ITO-coated glass substrates under cross-Nicol conditions. The cell gap between ITO-coated glass substrates is about $15 \mu \mathrm{m}$. In $\mathrm{C}_{6} \mathrm{PcH}_{2}$ many large crystal domains of more than $200 \mu \mathrm{m}$ in length were observed. The high ambipolar carrier mobility, $1.08 \mathrm{~cm}^{2} / \mathrm{Vs}$ for hole and $0.5 \mathrm{~cm}^{2} / \mathrm{Vs}$ for

Table 1 Alkyl-substituent length dependence of performance parameters in current density-voltage characteristics of solar cells with ITO/PEDOT:PSS/ $\mathrm{CnPcH}_{2}: \mathrm{PCBM} / \mathrm{Al}$ structures under AM1.5G $\left(100 \mathrm{~mW} / \mathrm{cm}^{2}\right)$ solar-illuminated conditions.

\begin{tabular}{lcccc}
\hline \hline Material of active layer & $V_{\text {oc }}(\mathrm{V})$ & $l_{\mathrm{sc}}\left(\mathrm{mA} / \mathrm{cm}^{2}\right)$ & Fill factor & $\eta_{e}(\%)$ \\
\hline $\mathrm{C} \mathrm{PcH}_{2}$ & 0.80 & 6.75 & 0.410 & 2.22 \\
$\mathrm{C} 7 \mathrm{PcH}_{2}$ & 0.66 & 4.82 & 0.290 & $0.92 \mathrm{C} 9 \mathrm{PcH}_{2}$ \\
$\mathrm{C}_{\mathrm{PcH}}$ & 0.63 & 1.90 & 0.284 & 0.34 \\
$\mathrm{C} 10 \mathrm{PcH}_{2}$ & 0.59 & 1.81 & 0.293 & 0.31 \\
\hline \hline
\end{tabular}



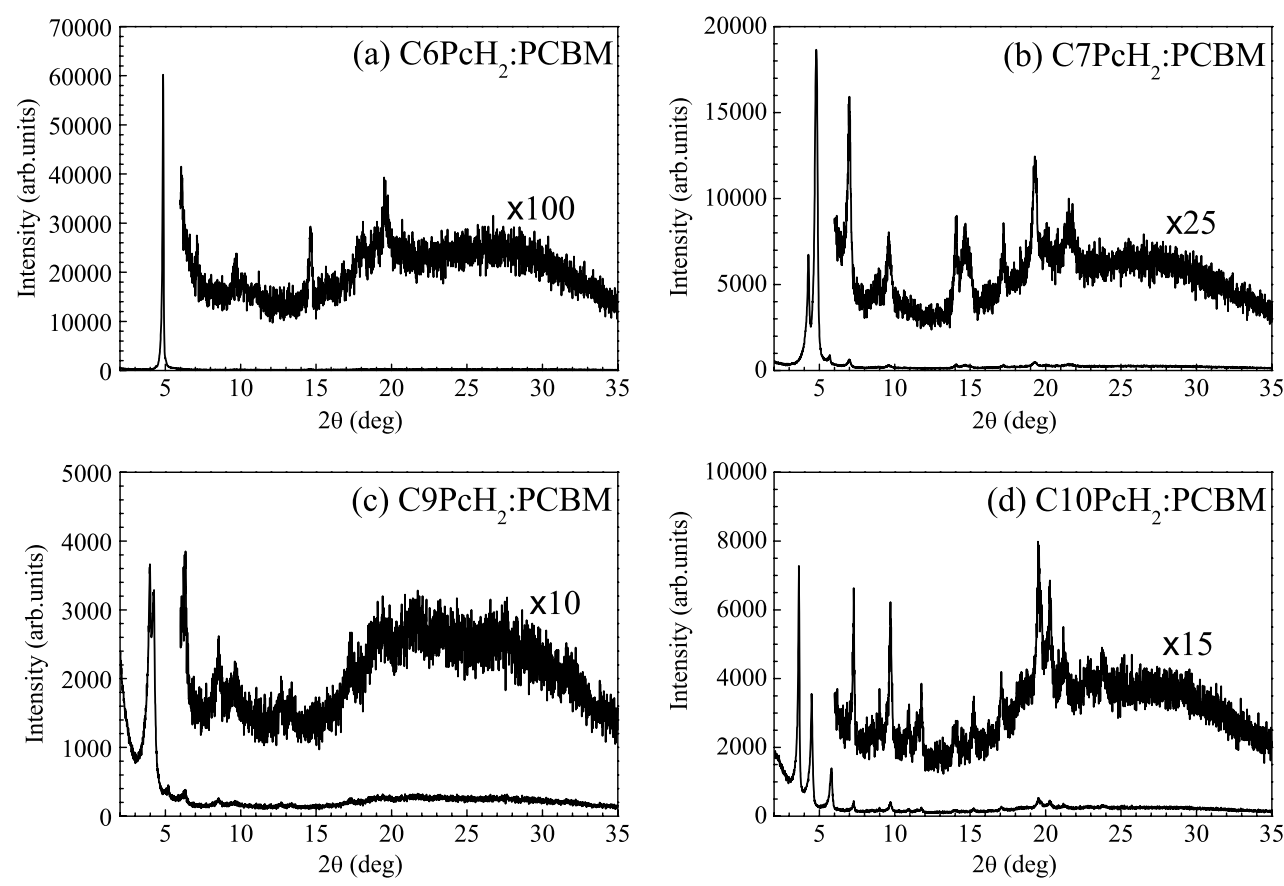

Fig. 4 XRD patterns of (a) $\mathrm{C} \mathrm{PCH}_{2}: \mathrm{PCBM}$, (d) $\mathrm{C}_{10 \mathrm{PcH}_{2}}: \mathrm{PCBM}$ bulk heterojunction films.

(b) $\mathrm{C}_{\mathrm{PcH}}: \mathrm{PCBM}$ (c) $\mathrm{CPPcH}_{2}: \mathrm{PCBM}$, and

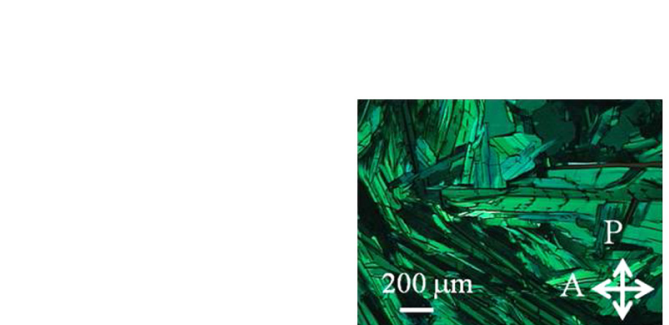

(a) $\mathrm{C}_{6 \mathrm{PcH}}$

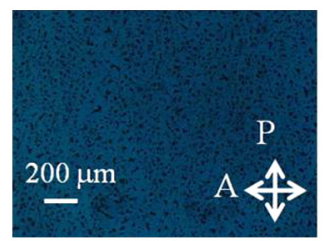

(c) $\mathrm{C}_{9} \mathrm{PcH}_{2}$

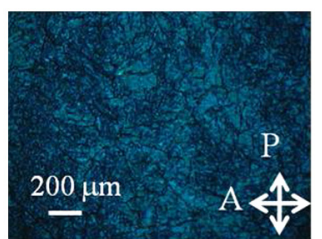

(b) $\mathrm{C}_{7} \mathrm{PcH}_{2}$

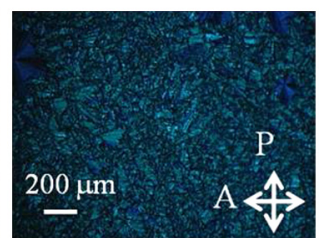

(d) $\mathrm{C}_{10 \mathrm{PcH}_{2}}$

Fig. 5 Polarizing photomicrographs of (a) $\mathrm{C}_{6 \mathrm{PcH}}$, (b) $\mathrm{C} 7 \mathrm{PcH}_{2}$, (c) $\mathrm{C} \mathrm{PcH}_{2}$, and (d) $\mathrm{C}_{10 \mathrm{PcH}_{2}}$ at temperature of $25^{\circ} \mathrm{C}$ between ITO-coated glass substrates (cell gap, about $15 \mu \mathrm{m}$ ) under cross-Nicol conditions.

electron, was evaluated by the TOF technique. In the other $\mathrm{CnPcH}_{2}$ 's, however, many small domains were observed, and carrier mobility could not be evaluated by the TOF technique, because of the dispersive decay curves of the transient. It is thought that the deep carrier trap at domain boundaries must be one reason for the dispersive decay curves of transient photocurrent observed in $\mathrm{C}_{\mathrm{PcH}}, \mathrm{C}_{2} \mathrm{PcH}_{2}$, and $\mathrm{C}_{10 \mathrm{PcH}_{2}}$. It is considered that the photovoltaic properties of the solar cell utilizing $\mathrm{C}_{6} \mathrm{PcH}_{2}$ are the highest because of the excellent electrical properties of large crystal domains with single hexagonal columnar structure alignment.

\section{Conclusion}

Bulk heterojunction organic thin-film solar cells utilizing the soluble phthalocyanine derivatives $\mathrm{C}_{6 \mathrm{PcH}}, \mathrm{C}_{7} \mathrm{PcH}_{2}, \mathrm{C}_{9} \mathrm{PcH}_{2}$, and $\mathrm{C}_{10 \mathrm{PcH}_{2}}$ were investigated. We found that the absorption 
Hori et al.: Dependence of alkyl-substituent length for bulk heterojunction...

coefficient spectra were independent of substituent length in a solution condition and that the electronic energy states are independent of substituent length in an isolated condition in the solution. The absorbance spectra of thin films at the Q-band region differed between $\mathrm{C}_{6 \mathrm{PcH}_{2}}$ and the other $\mathrm{CnPcH}_{2}$ 's, however, and the different alignment of molecules in the $\mathrm{C}_{6 \mathrm{PcH}}$ film as compared with the other $\mathrm{CnPcH}_{2}$ films contributes to each electronic state. Two broad peaks exist in the EQE spectra, which almost correspond to the Q-band and B-band of $\mathrm{CnPcH}_{2}$. The solar cell utilizing $\mathrm{C} \mathrm{PcH}_{2}$ has the highest photovoltaic properties in all parameters of $V_{\mathrm{oc}}, I_{\mathrm{sc}}, \mathrm{FF}$, and $\eta_{e}$. Almost the same photovoltaic properties were observed in the solar cells utilizing $\mathrm{C}_{9} \mathrm{PcH}_{2}$ and $\mathrm{C} 10 \mathrm{PcH}_{2}$. From the results of XRD measurement and polarization microscope observation, we found that $\mathrm{C} \mathrm{PcH}_{2}$ formed a hexagonal columnar structure and had many large crystal domains of more than $200 \mu \mathrm{m}$ in length. On the other hand, other $\mathrm{CnPcH}_{2}$ 's formed a rectangular columnar structure and had many small domains with various alignments. The crystalline structure accounts for differences in the electrical properties of all $\mathrm{CnPcH}_{2}$ 's and makes $\mathrm{C} \mathrm{PcH}_{2}$ : $\mathrm{PCBM}$ bulk heterojunction film superior; therefore, the solar cell utilizing $\mathrm{C} \mathrm{PcH}_{2}$ displays the best photovoltaic properties.

\section{Acknowledgments}

This work was partly supported by Grants-in-Aid, for Young Scientists (A), and for the Japan Society for the Promotion of Science Fellows (No. 225630) from the Ministry of Education, Culture, Sports, Science and Technology, Japan, and by the Global Center of Excellence (Global COE) Program "Center for Electronic Devices Innovation" at Osaka University.

\section{References}

1. C. W. Tang, "Two-layer organic photovoltaic cell," Appl. Phys. Lett. 48(2), 183-185 (1985), http://dx.doi.org/10.1063/1.96937.

2. S. Morita, A. A. Zakhidov, and K. Yoshino, "Doping effect of buckminsterfullerene in conducting polymer: change of absorption spectrum and quenching of luminescence," Solid State Commun. 82(4), 249-252 (1992), http://dx.doi.org/10.1016/0038-1098(92)90636-N.

3. N. S. Sariciftci et al., "Photoinduced electron transfer from a conducting polymer to buckminsterfullerene," Science 258(5087), 1474-1476 (1992), http://dx.doi.org/10.1126/science .258.5087.1474.

4. K. Yoshino et al., "Enhanced photoconductivity of $\mathrm{C}_{60}$ doped poly(3-alkylthiophene)," Solid State Commun. 85(2), 85-88 (1993), http://dx.doi.org/10.1016/0038-1098(93) 90352-N.

5. G. Yu et al., "Polymer photovoltaic cells: enhanced efficiencies via a network of internal donor-acceptor heterojunctions," Science 270(5243), 1789-1791 (1995), http://dx.doi.org/ 10.1126/science.270.5243.1789.

6. Y. Liang et al., "For the bright future-bulk heterojunction polymer solar cells with power conversion efficiency of 7.4\%," Adv. Mater. 22(20), E135-E138(2010), http://dx.doi.org/10 $.1002 /$ adma.200903528.

7. F. C. Krebs, J. Fyenbo, and M. Jørgensen, "Product integration of compact roll-to-roll processed polymer solar cell modules: methods and manufacture using flexographic printing, slot-die coating and rotary screen printing," J. Mater. Chem. 20(41), 8994-9001 (2010), http://dx.doi.org/10.1039/c0jm01178a.

8. M. Hiramoto, H. Fujiwara, and M. Yokoyama, "Three-layered organic solar cell with a photoactive interlayer of codeposited pigments," Appl. Phys. Lett. 58(10), 1062-1064 (1991), http://dx.doi.org/10.1063/1.104423.

9. B. Walker, C. Kim, and T. Quyen-Nguyen, "Small molecule solution-processed bulk heterojunction solar cells," Chem. Mater. 23(3), 470-482 (2011), http://dx.doi.org/10.1021/ cm102189g.

10. Y. Miyake et al., "High carrier mobility up to $1.4 \mathrm{~cm}^{2} \mathrm{~V}^{-1} \mathrm{~s}^{-1}$ in non-peripheral octahexyl phthalocyanine," Appl. Phys. Express 4(2), 021604-1-021604-3 (2011), http://dx.doi.org/ 10.1143/APEX.4.021604. 
11. Y. Miyake et al., "Liquid crystalline phthalocyanines as a self-assembling organic semiconductor for solution-processing thin film devices," Proc. SPIE 7955, 795505 (2011), http:// dx.doi.org/10.1117/12.873717.

12. M. J. Cook et al., " $1,4,8,11,15,18,22,25$-Octa-alkyl phthalocyanines: new discotic liquid crystal materials," J. Chem. Soc. Chem. Commun. 1987(14), 1086-1087 (1987), http:// dx.doi.org/10.1039/C39870001086.

13. T. Hori et al., "Solution processable organic solar cell based on bulk heterojunction utilizing phthalocyanine derivative," Appl. Phys. Express 3(10), 101602-1-101602-3 (2010), http:// dx.doi.org/10.1143/APEX.3.101602.

14. T. Hori et al., "Bulk heterojunction organic solar cells utilizing 1,4,8,11,15,18,22,25octahexylphthalocyanine," Sol. Energy Mater. Sol. Cells 95(11), 3087-3092 (2011), http://dx.doi.org/10.1016/j.solmat.2011.06.039.

15. N. Yamasaki et al., "Solution flow assisted fabrication method of oriented-conjugated polymer films by using geometrically-asymmetric sandwich structures," Jpn. J. Appl. Phys. 50 (2), 020205-1-020205-3 (2011), http://dx.doi.org/10.1143/JJAP.50.020205.

16. H. Iino et al., "Very high time-of-flight mobility in the columnar phases of a discotic liquid crystal,” Appl. Phys. Lett. 87(13), 132102-1-132102-3 (2005), http://dx.doi.org/10.1063/1 .2056608 .

17. H. Iino et al., "Fast ambipolar carrier transport and easy homeotropic alignment in a metalfree phthalocyanine derivative," Jpn. J. Appl. Phys. 44, L1310-L1312 (2005), http://dx.doi .org/10.1143/JJAP.44.L1310.

18. J. C. Swarts et al., "Synthesis and electrochemical characterisation of some long chain $1,4,8,11,15,18,22,25$-octa-alkylated metal-free and zinc phthalocyanines possessing discotic liquid crystalline properties," J. Mater. Chem. 11(2), 434-443 (2001), http://dx.doi.org/ 10.1039/B006123I .

19. A. Fujii et al., "Two-band electroluminescent emission in organic electroluminescent diode with phthalocyanine film," Jpn. J. Appl. Phys. 35, L37-L39 (1996), http://dx.doi.org/10 .1143/JJAP.35.L37.

Biographies and photographs of the authors are not available. 